\title{
o Fim do Homem Soviético de Svetlana Aleksievitch, ou o fim da grande utopia
}

\section{José Eduardo Reis}

Universidade de Trás-os-Montes e Alto Douro - ILC

\section{Acerca da História}

IV

Radical e Reaccionário vivem juntos como num casamento

miserável,

diminuídos um pelo outro, encostados um ao outro.

Mas nós, os seus filhos, temos de encontrar o nosso caminho.

Cada problema exige a sua linguagem privada.

Por qualquer vereda em que haja um traço de verdade, caminhem.

Tomas Tranströmer

A versão portuguesa de $O$ Fim do Homem Soviético (Um Tempo em Segunda Mão), o único livro publicado em Portugal aquando da atribuição do prémio Nobel de 2015 à escritora e jornalista bielorussa Svetlana Aleksievitch, inclui uma "conversa conduzida por Natália Igrunova". É um paratexto que situado no epílogo desta obra cumpre uma função 
editorial importante, a de dar a conhecer o tom geral, a motivação estética e o programa narrativo da produção literária daquela autora sobre a "Grande Utopia” do século XX, a da inaugural tentativa de construção do homem novo modulado pela ideologia marxistaleninista soviética. Num registo que poderíamos designar de trágico-prosaico, essa "enciclopédia vermelha", na expressão de Svetlana, surge representada em cinco livros, o primeiro dos quais, A Guerra Não Tem Cara de Mulher (1984), incidindo sobre testemunhos épicos e de horror de mulheres suas compatriotas sobre o que viveram e sofreram na II Guerra Mundial; o segundo, As Últimas Testemunhas (1985), dando continuidade ao mesmo tema, mas tendo como protagonistas crianças soviéticas; o terceiro, Os Rapazes de Zinco (1989), baseado em relatos de guerra de jovens soldados soviéticos que combateram em território afegão; o quarto, A Oração de Chernobil (1997), discorrendo sobre as tremendas consequências políticas e ideológicas e sobre os nefastos prejuízos para a saúde pública e para o meio ambiente provocados pela explosão ocorrida em 1986 de um reactor da central nuclear soviética de Chernobil - topónimo que passou a símbolo universal dos perigos incontroláveis e imprevisíveis associados à tecnologia e ao uso da energia atómica; por último, o referido O Fim do Homem Soviético (2012) focado também nos efeitos sociais e culturais de outro colapso, o do sistema e do império político soviéticos. Cada um desses livros documenta os efeitos de acções humanas catastróficas com uma forte ressonância simbólica na história do mundo contemporâneo e cada um deles tem como protagonista ou personagem principal colectiva o povo russo.

Se olharmos retrospectivamente - diz Svetlana noutro contexto - para a totalidade da nossa história, quer a soviética, quer a pós-soviética, ela é uma imensa vala comum e um rio de sangue. Um eterno diálogo entre os executores e as vítimas. As amaldiçoadas questões russas: o que fazer, a quem culpar. A revolução, os gulags, a segunda guerra mundial, a guerra soviética-afegã que foi escondida do povo, a queda do grande império, a queda da gigante terra socialista e agora o desafio de dimensões cósmicas - Chernobyl. Isto é um desafio para tudo o que tem vida na terra. Eis a nossa história. E é este o tema dos meus livros, o meu caminho, os círculos do meu inferno, de homem para homem. (in: "The chronicler of the utopian land")

Se o povo russo e a sua história recente e contemporânea, pelo elevado índice de 
situações trágicas e multiformes expressões de sofrimento que protagonizaram, ocupam o primeiro plano e assumem um papel central na escrita de Svetlana Aleksievitch (respondendo a uma pergunta de Natália Igrunova, diz: "Mas que somos pessoas de desgraça e do sofrimento é a cultura russa profunda e antiga. Vai pelo campo e fala em qualquer cabana. De que é que falarão? Só da desgraça [...] 0 sofrimento, a luta e a guerra, tal é a experiência da nossa vida e da nossa arte." (Aleksievitch, 2015: 465), o facto é que essa quase fatalidade trágica nacional documentada nos seus livros funciona por metonímia, pelo seu valor de referência, pela sua qualidade ilustrativa, como um temática ressonante e articulável com outras circunstâncias históricas, políticas e nacionais. Como se naquele "ciclo de livros sobre a Utopia" pulsasse uma matéria narrativa essencial e de teor universalizante susceptível de ser comparada, evocada e traduzida; como se ao falar dos efeitos da insensatez e dos desmandos da experiência política soviética esses livros esclarecessem ou prefigurassem as razões da ocorrência de eventos sucedidos ou ainda por suceder noutros tempos e lugares, noutras cronologias e geografias culturais, tal a sua capacidade exemplar, a fiabilidade da sua escala de aferição, o seu valor de modelo em lhes conferir significado. Tanto retrospectiva como prospectivamente, os efeitos da leitura dos livros de Svetlana tendem a cumprir essa função catártica que a grande literatura trágica pode desempenhar junto dos cidadãos que livremente se auto-incluem na polis da cultura governada pela força da consciência crítica e examinadora do peso da história, das ilusões ideológicas coevas e dos mitos do progresso futuro. Por isso, Os Rapazes de Zinco, sobre a guerra do Afeganistão, foi lido em França à luz da guerra da Argélia, enquanto na América o foi à luz do 11 de Setembro; já a Oração de Chernobil, em França, inspirou dramaturgias e performances como forma de alertar para um potencial desastre nuclear numa das muitas centrais atómicas situadas no seu território, enquanto no Japão foi reeditado após o desastre de Fukushima.

Falámos de catarsis - que na poética clássica aristotélica significava a experiência estética sublimadora das paixões de terror e piedade vividas pelos cidadãos gregos que assistiam às representações das tragédias -, conceito que nos parece adequado para definir a recepção estética, sobretudo entre os seus compatriotas, da obra literária de Svetlana 
Aleksievitch. Para definir as condições, não da recepção, mas da produção romanesca desta autora, falemos agora de mimesis, outro conceito clássico também teorizado, na esteira de Platão, por Aristóteles para caracterizar a natureza específica da tragédia teatral e que, por extensão, serve ainda, com as devidas actualizações e revisões teóricas, para explicitar os mecanismos de representação literária. A arte imita a natureza era o dictum do estagirita para explicar quanto a literatura se devia ocupar em figurar verbalmente o mundo. A obra literária de Svetlana revê-se neste conceito aristotélico de mimese, dele se apropriando para o reinventar de modo a ser o mais intencionalmente eficaz na produção de um discurso literário gerador de um efeito catártico na sua recepção estética. A sua técnica de escrita e o género em que a praticou ficou-a porém a dever à inovadora forma romanesca do designado "romance colectivo" ou "romance oratório", ou "romance evidência", ou "coro épico" originalmente inventado e cultivado pelo escritor bielorusso Aless Adámovitch, isto é, a uma modalidade narrativa que combina um conteúdo temático feito a partir de testemunhos plurais e diversificados sobre acontecimentos reais com uma expressão despojada de efeitos retóricos e marcada por um tom de oralidade. "Procurei o meu género - disse Svetlana - durante muito tempo para escrever da mesma maneira que o meu ouvido ouve. E quando li o livro [de Adámovitch] Sou uma aldeia de Fogo compreendi que isso era possível". O conjunto dos seus livros adopta, portanto, esse registo de oralidade, transcrito em cadências rítmicas de aparente simplicidade estilística, porém modeladas por recurso à exigente técnica narrativa do discurso indirecto e livre. No livro O Fim do Homem Soviético, e tanto quanto é possível avaliar pela elevada qualidade literária da tradução portuguesa de António Pescada, Svetlana pratica com mestria essa técnica dando assim expressão a uma vontade de representação mimética com uma evidente finalidade catártica.

Tendo nascido em 1948, a vencedora do Nobel da literatura de 2015 conheceu, aderiu, interiorizou, à semelhança de milhões de compatriotas seus e de milhões de outros cidadãos do mundo inteiro, a ideologia comunista como uma doutrina salvífica, infalível, inscrita nas leis de desenvolvimento necessário da história da humanidade. 0 seu desencanto e o seu posicionamento crítico relativamente a essa doutrina, que necessariamente impregnou a formação da sua personalidade, foram porém crescendo à 
medida que o seu alcance utópico passou a ser denegado pela evidência das contradições, dos absurdos, dos malefícios e das injustiças da sua aplicação real. 0 capítulo introdutório "Notas de uma Cúmplice" de O Fim do Homem Soviético, deixa, porém, implícita a ideia de que a opção da autora por "escutar todos os participantes do drama socialista" visou compor não um libelo mas um requiem por um regime político e um sistema económico e social cujo balanço tem de ser feito à luz do contexto histórico em que esse regime e sistema vigoraram e por contraste com os que lhes sucederam. Um contraste que tem por pedra de toque a ideia de liberdade, ideia que serviu de mote à pesquisa de Svetlana e que de modo assimétrico lhe permitiu estabelecer uma distinção estruturante entre as gerações de concidadãos que nasceram e os que não nasceram na URSS. À pergunta feita aos seus informantes, "O que é a liberdade?" as respostas dos pais e dos filhos não podiam ser mais contraditórias, dado que são "pessoas de planetas diferentes".

Os pais: a liberdade é a ausência de medo: três dias em Agosto quando vencemos o golpe; uma pessoa que escolhe numa loja entre cem variedades de salame é mais livre do que uma pessoa que escolhe entre dez variedades; não ser espancado, mas nunca chegaremos às gerações não espancadas; o homem russo não compreende a liberdade, precisa do cossaco e do látego. Os filhos: a liberdade é o amor; é a liberdade interior; um valor absoluto; quando não temos medo dos nossos desejos; ter muito dinheiro, e nesse caso teremos tudo; quando se pode viver de tal maneira; quando se pode viver de tal maneira que não se pensa na liberdade. A liberdade é o normal. (14)

Podemos então dizer que $O$ Fim do Homem Soviético é uma narrativa que se constrói por multiformes variações testemunhais sobre a ausência, denegação, ilusão ou vulgarização do tema da aspiração à vivência da liberdade. Concebida, entre a apologia e a execração, como um requiem pela figuração política desse supremo valor humano, é uma narrativa circunscrita à rememoração do apogeu e queda do regime soviético num tempo ulterior de desencanto e desorientação ideológicos. Ou, para utilizarmos outra designação, é um políptico em dois painéis ordenados segundo um esquema bipolar de intensidades de luz esperançosa e de sombra trágica projectadas quer sobre a utopia da construção do homem novo, justo, igualitário e comunista, quer sobre a utopia a do homem pós-soviético, 
liberal, democrático, consumista. Esse esquema bipolar estrutura e ordena $O$ Fim do Homem Soviético em vários planos temáticos e discursivos, distribuídos pelas 20 histórias que integram as duas discretas partes (os dois grandes andamentos do requiem ou as duas grandes tábuas do políptico) intituladas respectivamente, “Consolação pelo apocalipse” e o "Encanto do Vazio". Cada uma dessas partes é temporalmente delimitada pelos dez anos que decorreram entre 1991 e 2001 - os anos de governo de Gorbatchov e de Eltsin -, isto é, entre o golpe de Agosto que precipitou o fim do regime comunista soviético e as tentativas de criação de um regime democrático e de uma economia de mercado na Federação Russa e o decénio de 2002 a 2012 - os anos de consolidação da governação tendencialmente autocrata de Putin numa Rússia economicamente dominada pelos oligopólios e pelo agravamento das desigualdades sociais. A cada um desses decénios correspondem dez micro narrativas não dispostas cronologicamente, mas ordenadas de modo caleidoscópico, segundo uma lógica marcada pela contradição e pelos efeitos paradoxais do referido jogo de luzes e sombras inscrito na formulação antitética dos seus respectivos títulos. Exemplos: “A beleza da ditadura e o mistério da borboleta no cimento"; "Irmãos e irmãs, os carrascos e as vítimas ... e o eleitorado"; "As delícias do sofrimento e os caprichos do espírito russo"; "Uma velha com uma gadanha e uma rapariga bonita". Justapondo utopia e história, nostalgia e decepção, idealismo e pessimismo, liberdade e repressão, tragédia e farsa, coragem e delação, esperança e desilusão, cada uma dessas dez histórias é simbólica e ironicamente sobre intitulada pela predominância de um vector semântico que oscila entre duas possibilidades narrativas temporalmente balizadas por aqueles dois decénios: as que são contadas "num interior vermelho" e as que o são "sem decoração de interiores". As primeiras, "num interior vermelho", são as que reflectem a fé - “Quero morrer comunista. É o meu último desejo" (181), diz uma vítima das purgas estalinistas, Vassili Petróvitch, de 87 anos, membro do partido comunista desde 1922 -, mas também o terror associado à aplicação política do ideário comunista da ditadura do proletariado - “ quem éramos nós?, [pergunta retoricamente Marina Tíkhonovna, vizinha de Aleksandr Porfírevitch, 63 anos, marceneiro reformado, que se imolou pelo fogo, deprimido e alcoolizado por ter sido abandonado pela mulher e pela razão de viver o ideal comunista da URSS de que fora 
deputado] , "quem éramos nós?", "Inimigos do povo ... kulaks ou favoráveis aos kulaks . Na nossa aldeia todas as famílias remediadas foram deskulakizadas; se tinham dois cavalos e duas vacas já eram kulaks. Mandavam-nas para a Sibéria, abandonavam-nos ali na floresta da taiga ... As mulheres estrangulavam os filhos, para que não sofressem" (80). As segundas histórias, as narradas "sem decoração de interiores", são as que, exorbitando a influência histórica daquele universo de fé e terror vermelhos, traduzem, sem qualquer preocupação de realinhamento ou reorientação ideológica, a deriva axiológica e a corrupção moral causadas pela dissolução dos rígidos mecanismos de doutrinação leninista- estalinista. Diz a informante Alissa Z-er, directora de publicidade na narrativa "Uma solidão muito parecida com a felicidade":

Hoje é raro quem se deixe pasmar de amor. Consagram todas as forças a saltar! À carreira! Entre nós, na sala de fumo, as raparigas novas agitam-se, e se alguém tem um sentimento verdadeiro, têm pena dela: coitada, é parva, está lixada. [...] As agências turísticas de Moscovo propõem distracções especiais para clientes endinheirados e entediados]. Por exemplo dois dias na prisão [...] vestem-lhes roupas de presidiário empurram-nos pelo pátio com os cães e espancam-nos com um bastão de borracha [...] e eles ficam felizes. Experimentam novas sensações!” (333)

Essa dissolução dos valores políticos e ideais de fraternidade humana atingiria porém o seu momento mais paradoxalmente trágico com a irrupção dos preconceitos nacionais e dos conflitos étnicos provocados pela exaurir da força centrípeta do sistema de administração imperial e transnacional soviético. Comunica Gavkar Djuraeva, dirigente do Centro “A Migração e a Lei”: “Ano de 1992, em vez da liberdade que todos esperávamos começou a guerra civil. Os de Kuliab matavam os do Pamir, os do Pamir matavam os do Kuliab. Os de Karateguin, os de Guissar, os de Garm - todos se dividiam. Nas paredes dos prédios havia cartazes: "Russos, fora do Tajiquistão!, Comunistas vão-se embora para a vossa Moscovo" (385).

Ao longo desta narrativa há também um fio temático que a enleia e a atravessa e que diz respeito ao valor cultural e pedagógico da literatura enquanto território de conhecimento intelectual e estético do mundo dado e imaginado, enquanto veículo de 
resistência moral e de proclamação da incoercível liberdade do espírito humano e das suas reificações políticas e ideológicas. Esta isotopia da multímoda capacidade de conhecimento e revelação do fenómeno literário aflora logo no prólogo à parte I com um subtítulo que remete para personagens simbólicas dos contos populares russos "O parvo Ivánuchka e o Peixinho Dourado", representativos de um ímpeto nacional sonhador. E ocorre nos mais diversos contextos narrativos, seja, por exemplo, por recurso à estrofe popular com valor de incitação patriótica - "Desde a taiga ao mar do norte / o Exército Vermelho é o mais forte" (83) - ou de ilustração de situações líricas, melancólicas ou nostálgicas - “Crepita o lume no estreito fogão / Nas achas há lágrimas de resina, / E canta-me no abrigo o acordeão / Sobre os teus olhos de menina" (196) -, seja também por evocação da sua qualidade subversiva “Dantes ia-se parar à prisão por causa do Arquipélago Gulag. Liam-no em segredo, batiamno à máquina, copiavam-no à mão. Eu acreditava ... acreditava [diz Anna M, arquitecta, 59 anos] que se mil pessoas o lessem tudo mudaria" (260) - seja por reconhecimento dos ténues efeitos da sua função sapiencial - "Eu acreditava em Tchékhov ... [diz Aleksandr Laskovitch, soldado, empresário, emigrante entre os 21 e 30 anos] Foi ele que escreveu que o homem deve espremer de si o escravo até à última gota, e tudo nele será excelente: a alma, e as roupas, e os pensamentos. Mas acontece o contrário!” (362) -, seja ainda por alusão a um singular traço de carácter - " Mas agora devo falar-lhe de Iura [diz a realizadora Irina Vassíleva] ... Na aldeia chamam-lhe «o vaqueiro leitor» porque pastoreia as vacas e lê. Vi em casa dele muitos livros de filósofos russos" (429). Este imbricado fio temático dá o seu último ponto na última página da última narrativa "A coragem e o que vem depois" quando a informante, a jovem estudante Tânia Kulechova diz e questiona aludindo à prática das torturas infligidas contemporaneamente pelo regime ditatorial bielorusso: "Na escola diziam-nos. «Leiam Búnin, Tolstoi, esses livros salvam as pessoas». A quem se pode perguntar: porque é que isso não se transmite, e o puxador no ânus, ou o saco de plástico na cabeça se transmite?" (455).

Apesar do tom pessimista da pergunta final formulada neste requiem em dois andamentos ou neste políptico em duas tábuas, multicompostos por uma densa e ampla variedade de discretas mas articuláveis unidades temáticas, apesar da derradeira expressão 
fatalista inscrita nesta epopeia documental concebida a partir de fontes orais, de "vozes da rua" e de "conversas na cozinha", e que parece reconhecer o triunfo da força da barbárie sobre a subtil energia do espírito humano e da criatividade estética manifestada literariamente, a verdade é que a própria escrita da obra de Svetlana Aleksievitch é uma comprovação de que há livros como os seus que, se não salvam total e religiosamente os seus leitores, pelo menos permitem salvá-los da inconsciência de si, dos efeitos nefastos das suas ilusões, dos seus tédios, dos seus poderes, e de não se tornarem, por essa via, cúmplices da transmissão das mais variadas formas de sacos de plástico na cabeça.

\section{Bibliografia}

Aleksievitch, Svetlana (2015), O Fim do Homem Soviético, trad. António Pescada, Porto, Porto Editora.

-- (2015), "The chronicler of the utopian land", www.alexievich.info. 